\title{
Anti-Obesity Effects of Arum maculatum, Nasturtium officinale Plant Extracts and Exercise in High Fat Diet-Induced Obese Rats
}

\author{
Zana Hassan Ibrahim \\ Department of Medical Laboratory Science \\ College of Science \\ University of Raparin \\ Ranya, Iraq \\ zana@uor.edu.krd
}

\begin{tabular}{l}
\hline \hline Article Info \\
\hline Volume 6-Issue 2- \\
December 2021 \\
DOI: \\
10.24017/science.2021.2.18 \\
Article history: \\
Received 10/10/2021 \\
Accepted 1/2/2022 \\
\hline
\end{tabular}

Keywords:

Obesity, High fat diet, Rat model, Plant extracts, Arum maculatum, Nasturtium officinale and exercise.

\begin{abstract}
The Aim: To investigate and distinguish the anti-obesity activities of Arum maculatum, Nasturtium officinale plant extracts and exercise against high-fat diet induced obesity at rat model.

Methods: Thirty healthy male albino rats were randomly separated into 5 groups (n=6): Normal control (NC), high-fat diet control (HFD-C), Arum maculatum extract (AME), Nasturtium officinale extract (NOE) and exercise. The NC group fed with normal diet (ND) and all other groups a high fat diet (HFD) to induce obesity and hyperlipidemia for 8 weeks. Corresponding treatments were established to the respective groups during study period. Rat body weights $(B W)$ and food intake were obtained weekly. Glucose, Total cholesterol (TC), triglycerides (TG), low, very low and highdensity lipoprotein cholesterols (LDL-C, VLDL-C and HDL-C), malondialdehyde (MDA) with aspartate aminotransferase (AST) and alanine aminotransferase (ALT) were estimated in serum at the end of the study.

Results: The HFD-C rats were associated with a significant increase $(P<0.05)$ in $B W$ gain with the elevations in serum glucose, lipid profiles (TC, TG, LDL-C \&VLDL-C), liver function tests (AST \& ALT) and MDA in comparison with $N C$ rats although the level of serum HDL-C decreased. Furthermore, treatments of $A M E, N O E$ and exercise along with HFD significantly $(P<0.05)$ reduced HFD-induced changes in $B W$ gain and the levels of serum biochemical parameters as compared to rats fed HFD. The most significant effect on reducing weight gain at model rats were recorded by NOE treatment, while the attenuated effects AME on BW gain and AST, exercise on BW gain, TG, VLDL, MDA and AST were not significant $(P>0.05)$.

Conclusions: Consumption of HFD for 8 weeks caused HFD-C rats obese, hyperglycemic and hyperlipidemic with hepatic cellular injury when compared to the NC rats. AME, NOE and exercise treatments were suppressed the development of obesity as well as attenuated HFD induced changes in serum
\end{abstract}


biochemical parameters of the respective groups when compared to the HFD-C group.

\section{INTRODUCTION}

World Health Organization (WHO) defined obesity as abnormal body buildup of fat due to disturbance in balance between energy consumption and expenditure $[1,2]$. It considered as a serious public health issue around the globe that affecting both developed and under developing nations [3]. Occurrence of obesity is linked with the combination of several factors including genetic, nutritional, and environmental, A 2016 WHO survey stated that 1.9 billion adults were overweight worldwide, over 600 million of which are obese [4], more than 2.8 million individuals were die annually because of being overweight or obese [5]. Various health risks including metabolic syndrome diseases, some cardiovascular diseases and certain cancers has been confirmed to be associated with obesity [6]. The basic mechanisms for overcome or managing the obesity includes, food regimes, exercise and pharmaceuticals, the herbal medicines have great attention because of its natural source, low price and insignificant side effects [5]. Therapies for obesity through conventional drugs were linked with negative side effects and weight gain is rebound once the drug intake is ignored. Consequently, development of a safe and effective drug still in progress by researches to treat obesity [7]. In history, plant raw materials have served for construction of drugs, active compounds of several plants are extracted and used to treat numerous diseases [8]. In this context, the influence of Arum maculatum, Nasturtium officinale plant extracts and exercise on obesity were assessed at the present study.

\section{METHODS AND MATERIALS}

\subsection{Plant Material}

Arum maculatum and Nasturtium officinale fresh plants were collected around Ranya district in the month of March 2021. The whole plants were dried at room temperature away from sunlight, pulverized and supplied as a plant sample powders.

\subsection{Preparation of Plant Extracts}

Plant powders of Arum maculatum and Nasturtium officinale were separately extracted by hexane, ethyl acetate and ethanol $95 \%$ based on their polarity using a Soxhlet extractor. After exhaustive extractions (10 cycles, $100 \mathrm{gm} / 250 \mathrm{ml}$ solvent), the extracts of each plant from different solvents were filtered, concentrated completely by simple distillation process and mixed. The yields were $\sim 11.6$ and 8.9 gm respectively. The extracts were separately stored in airtight containers at refrigerator until use.

\subsection{Laboratory Animals}

Thirty male albino rats (Rattus norvegicus) of about 7-8 weeks of age and 195-210 gm BW were used. The experiment was achieved between Apr-2021 and Jun-2021 in the animal house of medical laboratory science department /Faculty of Science /Raparin University. The rats were kept in plastic cages bedded with wooden chips, maintained at a controlled temperature of $24 \pm 2 \mathrm{C}^{\mathrm{o}}$ with12-h light/dark cycles and fed according to study design with free access to water.

\subsection{Toxicity Investigations}

Investigations of toxicity for the two plant extracts were performed on 12 randomly selected animals. Rats were fasted overnight and divided into two equal groups, AME and NOE (300 $\mathrm{mg} / \mathrm{kg} \mathrm{BW}$ ) were orally administered respectively. The animals were examined continuously for 3 hours; lastly, overnight death if any was verified [3]. 


\subsection{Induction of Obesity}

Obesity was achieved through administration of HFD that prepared as described by study [9] and were supplied as a free access and basic diet for the respective experimental rats. This diet offers energy as fat $12 \%$; whereas the ND provides $4 \%$ as fat [10].

\subsection{Swimming Exercise Protocol}

Exercise protocol based on swimming as used by [11]. The rats of the exercised group were subjected to swimming in a plastic tank filled with tap water and drained after each swim. The water temperature is kept at $32 \pm 2 \mathrm{C}^{\mathrm{o}}$. A gradual progression for swimming was applied starting from 10 minutes, and then regularly protracted to $20,30,40,50$ minutes/day and the swimming exercise lasted 60 minutes on the sixth day, then swimming protocol began daily (1 hour, 6 days/ week) $[12,13]$, for 8 weeks. After completion of each swim, rats are air-dried and returned to their cages.

\subsection{Study Design}

After 1 week of acclimatization, Rats were randomly separated into five groups $(n=6)$.

Group I (NC): Fed ND for 8 weeks.

Group II (HFD-C): Fed HFD for 8 weeks.

Group III (HFD + AME): Fed HFD + Received AME (300 mg/kg B.W., 6 days/week) with oral gavage for 8 weeks.

Group IV (HFD + NOE): Fed HFD + Received NOE (300 mg/kg B.W., 6 days/week) with oral gavage for 8 weeks.

Group V: (HFD + Exercise): Fed HFD + Exercised (1 hour, 6 days/ week) for 8 weeks.

Except for NC, all other groups were fed with HFD along the study period. The HFD-C rats were regarded as a model group and treated with an equivalent volume of DW by oral gavage, food consumption and BW were recorded every week regularly along the study period. After the study was finished, overnight fasted animals were anesthetized by ethyl ether and blood samples were obtained through cardiac puncture. Serum was prepared by centrifugation (2500 RPM for 15 minutes) and examined for biochemical parameters.

\subsection{Measurement of biochemical Parameters}

The levels of serum glucose, TC, TG, HDL-C with AST and ALT concentrations were estimated by using full-auto analyzer (Cobas c-111). Serum MDA was measured photometrically with a TBA solution as described by [14] and the LDL and VLDL values were determined by applying the formula as follow:

LDL-cholesterol $(\mathrm{mg} / \mathrm{dl})=$ Total cholesterol $-(\mathrm{HDL}+$ Triglyceride/5) [4]

\subsection{Statistical Analysis}

The values of investigated parameters were analyzed by computer program (SPSS software version 26) and given as mean \pm standard error (mean $\pm \mathrm{SE}$ ). The differences between means were evaluated by Duncan's test through analysis of variance (ANOVA) and the differences were regarded as significant if $\mathrm{P}<0.05$.

\section{RESULTS}

\subsection{Effects of AME, NOE and exercise on body weight gain and food intake}

At the start of this work; mean BW of all experimental groups were approximately similar. Administration of HFD were associated with a significant increase $(\mathrm{p}<0.05)$ in BW of HFD$\mathrm{C}$ rats as compared to the $\mathrm{NC}$ animals, the percentages of $\mathrm{BW}$ gain were $83.243 \%$ and $70.531 \%$ respectively. (Table 1, Fig. $1 \& 2$ ).

After 8 weeks of the treatments, the BW of NOE rats fed HFD had gained (62.279\%) a significant $(\mathrm{p}<0.05)$ less BW than the HFD-C rats. Although treatments of AME and exercise showed lower BW gain, but the results were statistically not differed $(\mathrm{p}>0.05)$. (Table 1, Fig. 1 and 2).

The food intakes were not significantly changed between NC and HFD-C groups. Slight changes were detected between the HFD-C and the treatment groups (AME, NOE and exercise) but the differences were insignificant $(\mathrm{p}>0.05)$ too. (Table 1). 
Table 1: Effects of AME, NOE and exercise on BW gain and food consumption in high fat-fed rats for 8 weeks.

\begin{tabular}{|c|c|c|c|c|c|}
\hline \multirow{3}{*}{ Parameters } & \multirow{3}{*}{ NC } & \multicolumn{4}{|c|}{ High-fat diet-induced obese groups } \\
\hline & & \multirow[t]{2}{*}{ HFD-C } & \multirow[t]{2}{*}{ Exercise } & \multicolumn{2}{|c|}{ Plant extracts $(300 \mathrm{mg} / \mathrm{kg} \mathrm{BW})$} \\
\hline & & & & AME & NOE \\
\hline $\begin{array}{l}\text { Initial Body } \\
\text { Wt. (gm) }\end{array}$ & $195.63 \pm 4.53^{a}$ & $\begin{array}{r}198.25 \pm \\
7.20^{\mathrm{a}} \\
\end{array}$ & $203.36 \pm 5.13^{a}$ & $204.50 \pm 6.11^{a}$ & $201.11 \pm 3.42^{\mathrm{a}}$ \\
\hline $\begin{array}{l}\text { Final Body } \\
\text { Wt. (gm) }\end{array}$ & $\begin{array}{r}333.61 \pm \\
4.95^{\mathrm{ab}} \\
\end{array}$ & $\begin{array}{r}363.28 \pm \\
7.94^{c} \\
\end{array}$ & $\begin{array}{r}352.32 \pm \\
8.68^{\mathrm{bc}} \\
\end{array}$ & $347.26 \pm 2.86^{b c}$ & $326.36 \pm 5.21^{a}$ \\
\hline $\begin{array}{c}\text { Body Wt. gain } \\
(\%)\end{array}$ & 70.531 & 83.243 & 73.249 & 69.809 & 62.279 \\
\hline $\begin{array}{c}\text { Food intake } \\
\text { (g/week) }\end{array}$ & $129.32 \pm 4.28^{a}$ & $\begin{array}{r}129.47 \pm \\
7.77^{\mathrm{a}} \\
\end{array}$ & $135.59 \pm 7.35^{\mathrm{a}}$ & $123.81 \pm 5.09^{a}$ & $120.29 \pm 4.25^{a}$ \\
\hline
\end{tabular}

The same letters specify no significant differences; whereas the different letters is a sign of significant.

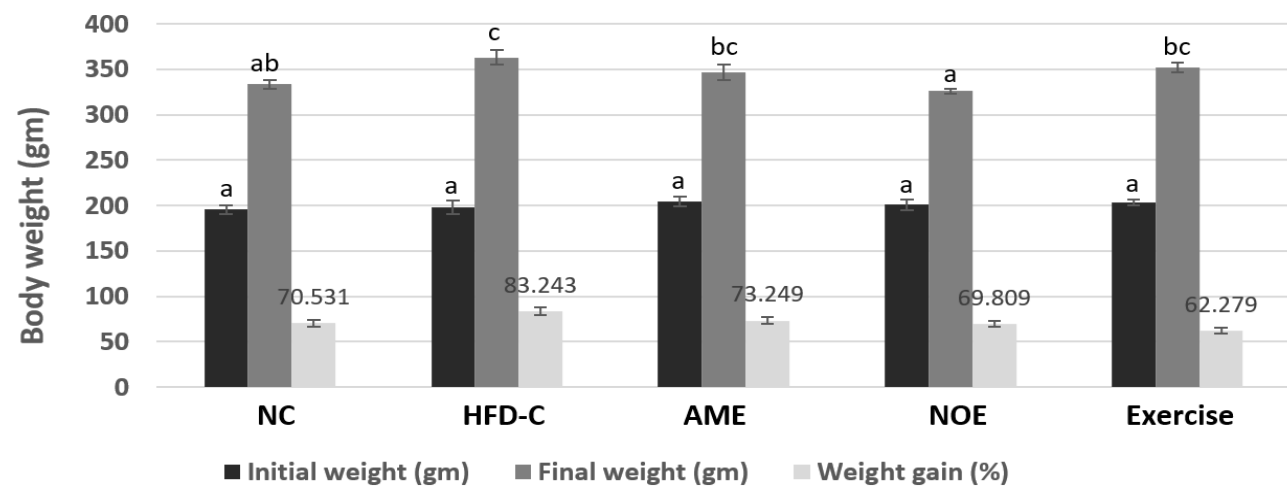

Figure 1: Effects of AME, NOE and exercise on body weight gain in high fat-fed rats for 8 weeks.

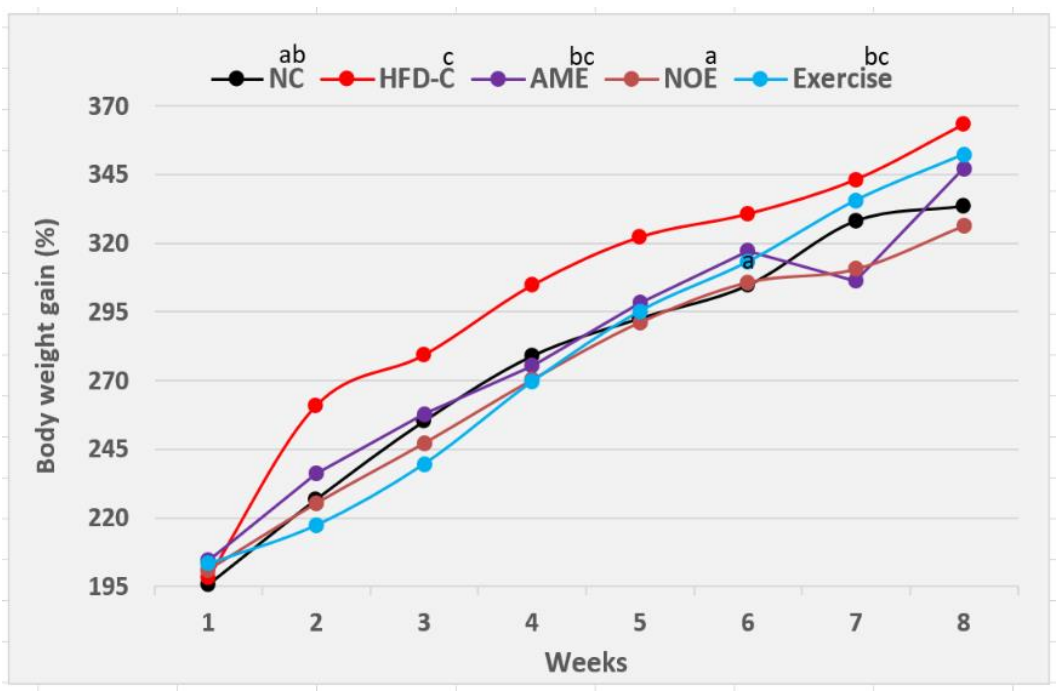

Figure 2: Effects of AME, NOE and exercise on BW gain/week in HFD-fed rats for 8 weeks. 


\subsection{Effects of AME, NOE and exercise on serum biochemical parameters}

The effects of AME, NOE and exercise on biochemical parameters in HFD-fed rats are illustrated at Table 2. Rats fed on a HFD were showed a significant hyperglycemia, hyperlipidemia with oxidative stress. Serum glucose, TC, TG, LDL, VLDL and MDA levels were significantly increased $(\mathrm{p}<0.05)$ while serum HDL level in HFD-C rats were decreased compared with rats fed a ND but did not reach statistically significant ( $\mathrm{p}>0.05)(\mathrm{Fig} 3)$.

Table 2: Effects of AME, NOE and exercise on biochemical parameters in high fat administrated rats for

\begin{tabular}{|c|c|c|c|c|c|}
\hline \multirow[t]{3}{*}{ Parameters } & \multirow[t]{3}{*}{ NC } & \multicolumn{4}{|c|}{ High-fat diet-induced obese groups } \\
\hline & & \multirow[t]{2}{*}{ HFD-C } & \multirow[t]{2}{*}{ Exercise } & \multicolumn{2}{|c|}{ Plant extracts $(300 \mathrm{mg} / \mathrm{kg} \mathrm{BW})$} \\
\hline & & & & AME & NOE \\
\hline $\begin{array}{l}\text { Glucose } \\
(\mathrm{mg} / \mathrm{dL})\end{array}$ & $92.65 \pm 5.71^{\mathrm{a}}$ & $147.03 \pm 8.52^{\mathrm{b}}$ & $113.55 \pm 11.2^{\mathrm{a}}$ & $117.33 \pm 10.53^{\mathrm{a}}$ & $102.40 \pm 7.82^{\mathrm{a}}$ \\
\hline TC (mg/dL) & $49.66 \pm 2.52^{a}$ & $72.66 \pm 5.02^{b}$ & $49.29 \pm 3.09^{a}$ & $50.68 \pm 2.83^{a}$ & $45.66 \pm 2.98^{a}$ \\
\hline TG (mg/dL) & $38.50 \pm 3.59^{b}$ & $75.20 \pm 1.88^{c}$ & $70.28 \pm 4.92^{c}$ & $28.88 \pm 2.53^{a}$ & $24.26 \pm 2.15^{a}$ \\
\hline $\begin{array}{c}\text { HDL-C } \\
(\mathrm{mg} / \mathrm{dL})\end{array}$ & $24.30 \pm 1.82^{\mathrm{ab}}$ & $21.31 \pm 3.66^{a}$ & $29.75 \pm 2.54^{c}$ & $28.79 \pm 1.66^{c}$ & $22.50 \pm 0.99$ bc \\
\hline LDL-C (mg/dL) & $7.70 \pm 0.71^{a}$ & $36.30 \pm 3.66^{c}$ & $5.47 \pm 1.09^{a}$ & $16.11 \pm 1.87^{b}$ & $18.30 \pm 3.24^{b}$ \\
\hline $\begin{array}{l}\text { VLDL-C } \\
\text { (mg/dL) }\end{array}$ & $7.73 \pm 0.88^{b}$ & $15.04 \pm 0.37^{c}$ & $14.05 \pm 0.98^{c}$ & $5.77 \pm 0.50^{a b}$ & $4.85 \pm 0.43^{a}$ \\
\hline MDA $(\mu \mathrm{mol} / \mathrm{l})$ & $1.695 \pm 0.04^{a}$ & $3.411 \pm 0.08^{c}$ & $3.020 \pm 0.12 \mathrm{bc}$ & $2.816 \pm 0.17^{b}$ & $2.060 \pm 0.25^{\mathrm{a}}$ \\
\hline AST (IU/L) & $86.53 \pm 6.38^{a}$ & $112.41 \pm 4.49 \mathrm{bc}$ & $127.58 \pm 4.88^{c}$ & $98.78 \pm 11.06^{\mathrm{ab}}$ & $79.16 \pm 6.41^{a}$ \\
\hline ALT (IU/L) & $23.56 \pm 0.98^{a}$ & $54.31 \pm 1.98^{d}$ & $36.56 \pm 1.37^{b}$ & $37.16 \pm 2.99 b$ & $45.20 \pm 0.98^{\circ}$ \\
\hline
\end{tabular}

Same letters mean the differences are insignificant; while the different letters mean significant. Comparing with the HFD-C group, all treatment groups were markedly restored the HFDinduced increases in serum lipid parameters, glucose and MDA, whereas serum HDL level was increased. The lowering effects of exercise treatment on TG, VLDL and MDA levels did not show a statistical difference ( $\mathrm{p}>0.05)$. (Fig. 3). 

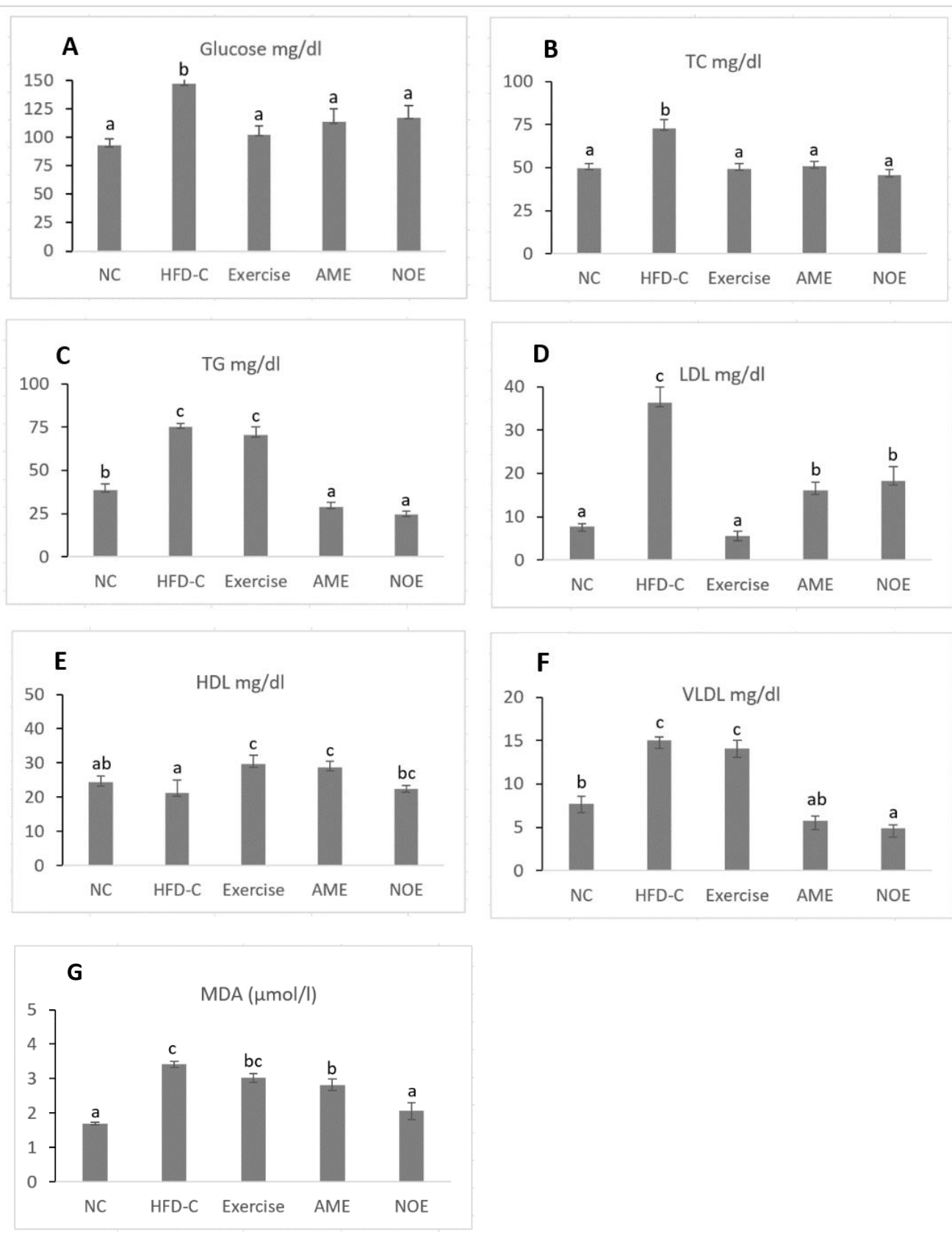

Figure 3: Effects of AME, NOE and exercise on levels of serum (A) glucose, (B) TC, (C) TG, (D) LDL, (E) HDL, (F) VLDL and (G) MDA in HFD-fed rats for 8 weeks.

Significant $(\mathrm{p}<0.05)$ elevations were observed in serum AST and ALT levels of model group as compared to NC group. The treatments were significantly $(\mathrm{p}<0.05)$ dropped the ALT level, meanwhile significant $(\mathrm{p}<0.05)$ decrease at serum AST level were just showed by NOE group; compared to that in the model group (fig 4). 

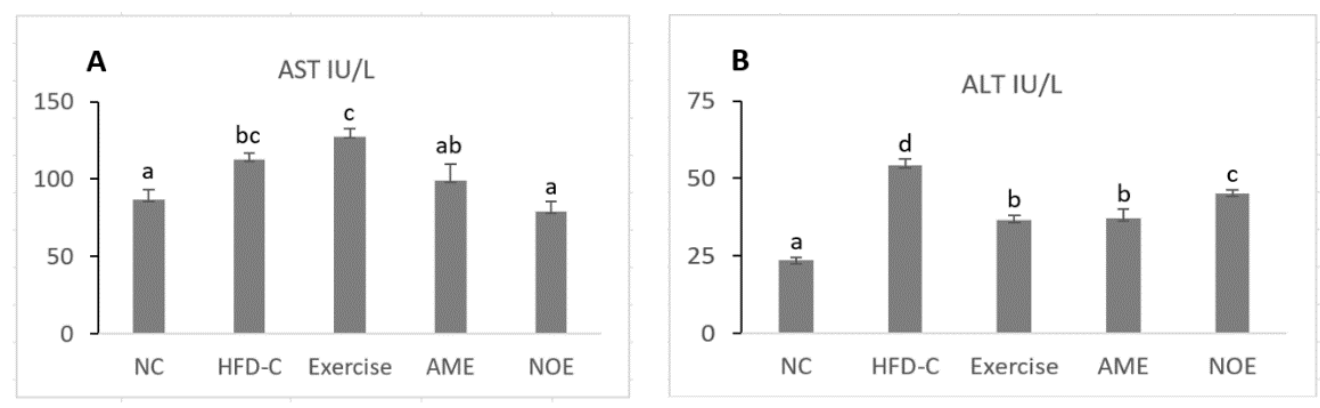

Figure 4: Effects of AME, NOE and exercise on serum levels of (A) AST and (B) ALT in rats fed on HFD for 8 weeks.

\section{DISCUSSION}

Diet-induced obesity studies in rodents are regarded as predominant model that reflecting the human obesity. Therefore, the first objective of current work was to create an obesity model at male Wistar rats, the next and the main objective is to examine the effects of AME, NOE and exercise on diet-induced obese rats to determine which of these treatments are able to reverse the increases in BW and hyperlipidemia exerted by HFD.

In the present study HFD-C rats revealed a significant increase in the BW gain, serum glucose, TC, TG, LDL-C and VLDL-C as compared with rats from NC without significant changes in the amount of food intakes while HDL reduces. These results clearly support the claim that administration of fat-rich diet could cause a marked weight gain, hyperglycemia and dyslipidemia. These findings were in accordance with the $[7,15,16]$ studies. Different possible mechanisms could stand behind the observed results. [17] argued that consumption of a HFD could facilitate a positive energy balance, leading to the development of obesity and hyperlipidemia because dietary fat is calorically dense. Besides, ingestion of fat promotes fat storage instead of fat oxidation or energy usage [18]. Furthermore, the energy intake was markedly higher in rats fed on HFD however the food intakes were approximately the same for all groups because of the higher fat content [19]. Hyperglycemia due to consumption of a HFD is because it lowers glucose uptake as well as inhibit liver to secrete glucose; as a result, leading to insulin resistance [3] and/or glucose intolerance [7].

The liver is chiefly act in lipid metabolism. It adjusts tissue fat deposition and levels of lipid in blood [20]. AST and ALT tests are good indicators for hepatic functional status [7]. During diet induced obesity, the elevations at serum ALT and AST of high fat-fed rats by this work could verify the alterations in normal hepatic function. The same results were documented by [4]. study [21] also confirmed that hyperlipidic food result in hepatic consequences in rats.

Serum MDA is an indication of lipid peroxidation [14], the close relationship between oxidative stress and extra fat feeding is well recognized [22]. Current study revealed that HFD-C rats faced an intensive oxidative stress, on the basis of serum MDA compared with $\mathrm{NC}$ rats. Several previous studies clarified that obesity is associated free-radical invention and/or weakened cellular antioxidant defense systems [23, 24].

It is well known that different strategies could be used in the prevention of obesity including lifestyle changes, behaviour therapy, pharmacotherapy and surgical operations [16]. Phytochemicals presently have a great prospect for the building up of future therapeutics [25], as they had patent role in defending against metabolic diseases in both animal and human [4]. This study aimed two of edible plants from Iraqi Kurdistan in the prevention of obesity as well as swimming exercise.

Data of the present study clearly displayed that rat fed HFD and simultaneously treated with AME, NOE and exercise separately were recorded a significant less BW gain, improved sugar and lipid profiles comparative to untreated HFD-fed rats (Table 1 and 2). Controlling the HFD-induced BW gain at this study since food intakes were approximately the same among 
the groups may be suggested that AME and NOE treatments diminished dietary fat absorption at intestine by suppressing the actions of pancreatic lipase enzyme [3]. In addition, it is known that the ingested fat in intestine is taken after it converted to chylomicrons by the help of lipase enzyme [26], moreover [6] stated that the blockage of triglyceride absorption plays a central role in weight loss, furthermore the loss of BW does not depend on food or energy intake when same quality and quantity of food was received by rats [17]. Exercise is helpful for the suppression of diet-induced obesity [27] as it confirmed by the results of current study. The mechanism by which exercise treatment reduced weight gain is through metabolic modulation or increased energy expenditure.

Results of the current study on biochemical parameters suggested that our treatments could lessening the hyperglycemia, hyperlipidemia and hepatic misfunctioning exerted by HFD feeding. The reduction of dyslipidemia can be attributed to stoppage of irregular fat deposition in adipocytes and other obesity-related abnormalities [2]. Two more possible mechanisms behind the hypolipidemic effects as described by [5] there might be a reduction in cholesterol uptakes from the intestine or disrupt the cholesterol manufacture. [1] proved that polyphenols could negatively effect on adipocyte differentiation, lipogenesis, lipid absorption as well as induce fatty acid oxidation. Decreased blood glucose and improved insulin sensitivity by plant extracts and exercise in obese rats as explained by [28] was probably by maintaining a balanced cell energy modulation or falling free fatty acids. Achievement of treatments against obesity could be derived from sugar and lipid lowering actions, heightened lipolysis, as well as, diminished lipogenesis or enhanced fatty acid oxidation [29]. These mechanism actions also applicable to results of this study due to the existence of bioactive metabolites within the plants.

In preventive study the administration of both plant extracts orally and swimming exercise on obese rats potentially effective in ameliorating the diet induced elevations of serum ALT, AST and MDA levels. Although the effects of AME and exercise were not significant, results indirectly suggest that the respective treatments could reverts the hepatic cell damages caused by obesity. The particular mechanism is unclear but it may belong to their known antioxidant effects [21] or phytochemical contents of the plants [4].

In current study exercised rats were unable to lower the levels of lipid peroxidation when compared to control group. Addition to numerous health benefits of exercise, strong evidence signifying that high-intensity exercise led to oxidative stress and significant elevation in level of MDA in both animals and human [30].

\section{CONCLUSION}

The AME, NOE and exercise can be used a potential therapeutic agent or dietary supplement against obesity and its correlated physiological consequences.

\section{REFERENCE}

[1] N. Boqué, J. Campión, R. de la Iglesia, A. L. de la Garza, F. I. Milagro, B. San Román, Ó. Bañuelos, and J. A. Martínez, "Screening of polyphenolic plant extracts for anti-obesity properties in Wistar rats," Journal of the Science of Food and Agriculture, vol. 93, no. 5, pp. 1226-1232, 2013.

[2] J. H. Kim, O.-K. Kim, H.-G. Yoon, J. Park, Y. You, K. Kim, Y.-H. Lee, K.-C. Choi, J. Lee, and W. Jun, "Anti-obesity effect of extract from fermented Curcuma longa L. through regulation of adipogenesis and lipolysis pathway in high-fat diet-induced obese rats," Food \& nutrition research, vol. 60, no. 1, pp. 30428,2016

[3] Z. A. Malik, and P. L. Sharma, "An ethanolic extract from licorice (glycyrrhiza glabra) exhibits antiobesity effects by decreasing dietary fat absorption in a high fat diet-induced obesity rat model," International Journal of Pharmaceutical Sciences and Research, vol. 2, no. 11, pp. 3010, 2011.

[4] L. Mabrouki, I. Rjeibi, J. Taleb, and L. Zourgui, "Cardiac ameliorative effect of Moringa oleifera leaf extract in high-fat diet-induced obesity in rat model," BioMed research international, vol. 2020, 2020.

[5] H. A. Rahman, N. G. Sahib, N. Saari, F. Abas, A. Ismail, M. W. Mumtaz, and A. A. Hamid, "Anti-obesity effect of ethanolic extract from Cosmos caudatus Kunth leaf in lean rats fed a high fat diet," BMC complementary and alternative medicine, vol. 17, no. 1, pp. 1-17, 2017. 
[6] F. Lei, X. Zhang, W. Wang, D. Xing, W. Xie, H. Su, and L. Du, "Evidence of anti-obesity effects of the pomegranate leaf extract in high-fat diet induced obese mice," International journal of obesity, vol. 31, no. 6, pp. 1023-1029, 2007.

[7] R. Mopuri, M. Ganjayi, K. S. Banavathy, B. N. Parim, and B. Meriga, "Evaluation of anti-obesity activities of ethanolic extract of Terminalia paniculata bark on high fat diet-induced obese rats," $B M C$ Complementary and Alternative medicine, vol. 15, no. 1, pp. 1-11, 2015.

[8] K. A. Oluyemi, I. O. Omotuyi, O. R. Jimoh, O. A. Adesanya, C. L. Saalu, and S. J. Josiah, "Erythropoietic and anti-obesity effects of Garcinia cambogia (bitter kola) in Wistar rats," Biotechnology and applied Biochemistry, vol. 46, no. 1, pp. 69-72, 2007.

[9] J. Wilding, S. Gilbey, M. Mannan, N. Aslam, M. Ghatei, and S. Bloom, "Increased neuropeptide Y content in individual hypothalamic nuclei, but not neuropeptide Y mRNA, in diet-induced obesity in rats," Journal of Endocrinology, vol. 132, no. 2, pp. 299-304, 1992.

[10] M. Brown, C. Bing, P. King, L. Pickavance, D. Heal, and J. Wilding, "Sibutramine reduces feeding, body fat and improves insulin resistance in dietary-obese male Wistar rats independently of hypothalamic neuropeptide Y," British journal of pharmacology, vol. 132, no. 8, pp. 1898-1904, 2001.

[11] O. Ciabattari, A. R. Dâmaso, M. Dal-Pai-Silva, and I. Freitas, "The Effect of the Aerobic Training on Morphological and Histochemical Characteristics of Tibial Anterior Muscle in Rats Fed with High Fat Diet," International Journal of Morphology, pp. 1053-1058, 2008.

[12] J. Karanth, and K. Jeevaratnam, "Effect of dietary lipid, carnitine and exercise on lipid profile in rat blood, liver and muscle," 2009.

[13] C.-C. Peng, K.-C. Chen, C.-L. Hsieh, and R. Y. Peng, "Swimming exercise prevents fibrogenesis in chronic kidney disease by inhibiting the myofibroblast transdifferentiation," PLoS One, vol. 7, no. 6, pp. e37388, 2012.

[14] R. H. Hussein, and Z. H. Ibrahim, "Influence of Omega-3 and Green Tea Extract on Alcohol-Induced Liver Injury in Rats," Kurdistan Journal of Applied Research, pp. 107-116, 2018.

[15] D. W. Lim, Y. T. Kim, Y.-J. Jang, Y.-E. Kim, and D. Han, "Anti-obesity effect of Artemisia capillaris extracts in high-fat diet-induced obese rats," Molecules, vol. 18, no. 8, pp. 9241-9252, 2013.

[16] B. Bati, I. Celik, A. Turan, N. Eray, E. E. Alkan, and A. K. Zirek, "Effect of isgin (Rheum ribes L.) on biochemical parameters, antioxidant activity and DNA damage in rats with obesity induced with highcalorie diet," Archives of Physiology and Biochemistry, pp. 1-9, 2020.

[17] Q. Li, Z. Liu, J. Huang, G. Luo, Q. Liang, D. Wang, X. Ye, C. Wu, L. Wang, and J. Hu, “Anti-obesity and hypolipidemic effects of Fuzhuan brick tea water extract in high-fat diet-induced obese rats," Journal of the Science of Food and Agriculture, vol. 93, no. 6, pp. 1310-1316, 2013.

[18] J. Flatt, E. Ravussin, K. J. Acheson, and E. Jequier, "Effects of dietary fat on postprandial substrate oxidation and on carbohydrate and fat balances," The Journal of clinical investigation, vol. 76, no. 3, pp. 1019-1024, 1985.

[19] M.-N. Woo, S.-H. Bok, M.-K. Lee, H.-J. Kim, S.-M. Jeon, G.-M. Do, S. K. Shin, T. Y. Ha, and M.-S Choi, "Anti-obesity and hypolipidemic effects of a proprietary herb and fiber combination (S\&S PWH) in rats fed high-fat diets," Journal of medicinal food, vol. 11, no. 1, pp. 169-178, 2008.

[20] S. MEGURO, T. MIZUNO, K. ONIZAWA, K. KAWASAKI, H. NAKAGIRI, Y. KOMINE, J. SUZUKI, Y. MATSUI, T. HASE, and I. TOKIMITSU, "Effects of tea catechins on diet-induced obesity in mice," Journal of Oleo Science, vol. 50, no. 7, pp. 593-598, 2001.

[21] A. Abliz, Q. Aji, E. Abdusalam, X. Sun, A. Abdurahman, W. Zhou, N. Moore, and A. Umar, "Effect of Cydonia oblonga Mill. leaf extract on serum lipids and liver function in a rat model of hyperlipidaemia," Journal of ethnopharmacology, vol. 151, no. 2, pp. 970-974, 2014.

[22] W.-S. Jang, Y.-S. Kim, and I.-C. Seol, "Antioxidant and Lipid-lowering Effects of Artemisia capillaris on a Rat Model of Hyperlipidemia," The journal of Korean medicine, vol. 33, no. 2, pp. 11-24, 2012.

[23] S. Olusi, "Obesity is an independent risk factor for plasma lipid peroxidation and depletion of erythrocyte cytoprotectic enzymes in humans," International journal of obesity, vol. 26, no. 9, pp. 1159-1164, 2002.

[24] S. C. Lima, R. F. Arrais, M. G. Almeida, Z. M. Souza, and L. F. Pedrosa, "Plasma lipid profile and lipid peroxidation in overweight or obese children and adolescents," Jornal de pediatria, vol. 80, pp. 23-28, 2004.

[25] R. B. Birari, and K. K. Bhutani, "Pancreatic lipase inhibitors from natural sources: unexplored potential," Drug discovery today, vol. 12, no. 19-20, pp. 879-889, 2007.

[26] M. E. Lowe, "Pancreatic triglyceride lipase and colipase: insights into dietary fat digestion," Gastroenterology, vol. 107, no. 5, pp. 1524-1536, 1994.

[27] Y. Ono, E. Hattori, Y. Fukaya, S. Imai, and Y. Ohizumi, “Anti-obesity effect of Nelumbo nucifera leaves extract in mice and rats," Journal of ethnopharmacology, vol. 106, no. 2, pp. 238-244, 2006.

[28] S. Obici, Z. Feng, G. Karkanias, D. G. Baskin, and L. Rossetti, "Decreasing hypothalamic insulin receptors causes hyperphagia and insulin resistance in rats," Nature neuroscience, vol. 5, no. 6, pp. 566$572,2002$.

[29] R. A. El-Shiekh, D. A. Al-Mahdy, S. M. Mouneir, M. S. Hifnawy, and E. A. Abdel-Sattar, "Anti-obesity effect of argel (Solenostemma argel) on obese rats fed a high fat diet," Journal of ethnopharmacology, vol. 238, pp. 111893, 2019.

[30] H. Pepe, "The effects of gender and exercise on malondialdehyde, nitric oxide and total glutathione levels in rat liver," African Journal of Pharmacy and Pharmacology, vol. 5, no. 4, pp. 515-521, 2011. 